Trauma Surgery \& Acute Care Open

\title{
Improvement in geriatric trauma outcomes in an evolving trauma system
}

\author{
Amund Hovengen Ringen, ${ }^{1,2}$ Iver Anders Gaski, ${ }^{3}$ Hege Rustad ${ }^{4}$ Nils Oddvar Skaga, \\ Christine Gaarder, ${ }^{3}$ Paal Aksel Naess ${ }^{2,3}$
}

\begin{abstract}
'Department of Anesthesia, Oslo University Hospital Ulleval, Oslo, Norway

2Institute of Clinical Medicine, Faculty of Medicine, University of Oslo, Oslo, Norway

${ }^{3}$ Department of Traumatology, Oslo University Hospital Ulleval, Oslo, Norway

${ }^{4}$ Department of GI-Surgery, Oslo University Hospital Ulleval, Oslo, Norway
\end{abstract}

Correspondence to Dr Amund Hovengen Ringen, Department of Anesthesia, Oslo University Hospital Ulleval, Oslo 0424, Norway; uxramu@ ous-hf.no

Received 23 November 2018 Revised 14 February 2019 Accepted 28 February 2019 (c) Author(s) (or their employer(s)) 2019. Re-use permitted under CC BY-NC. No commercial re-use. See rights and permissions. Published by BMJ.

To cite: Ringen $\mathrm{AH}$, Gaski IA, Rustad H, et al. Trauma Surg Acute Care Open 2019:4:e000282.

\section{ABSTRACT}

Background The elderly trauma patient has increased mortality compared with younger patients. During the last 15 years, initial treatment of severely injured patients at Oslo University Hospital Ulleval (OUHU) has changed resulting in overall improved outcomes. Whether this holds true for the elderly trauma population needs exploration and was the aim of the present study. Methods We performed a retrospective study of 2628 trauma patients 61 years or older admitted to OUHU during the 12-year period, 2002-2013. The population was stratified based on age (61-70 years, $71-80$ years, 81 years and older) and divided into time periods: 2002-2009 (P1) and 2010-2013 (P2). Multiple logistic regression models were constructed to identify clinically relevant core variables correlated with mortality and trauma team activation rate.

Results Crude mortality decreased from 19\% in P1 to $13 \%$ in $\mathrm{P} 2(\mathrm{p}<0.01)$ with an OR of $0.77(95 \% \mathrm{Cl} 0.65$ to 0.91 ) when admitted in $P 2$. Trauma team activation rates increased from $53 \%$ in $P 1$ to $72 \%$ in P2 $(p<0.01)$ with an OR of $2.16(95 \% \mathrm{Cl} 1.93$ to 2.41$)$ for being met by a trauma team in P2. Mortality increased from $10 \%$ in the age group $61-70$ years to $26 \%$ in the group above 80 years. Trauma team activation rates decreased from $71 \%$ in the age group $61-70$ years to $50 \%$ in the age group older than 80 years. Median ISS were 17 in all three age groups and in both time periods.

Discussion Development of a multidisciplinary dedicated trauma service is associated with increased trauma team activation rate as well as survival in geriatric trauma patients. As expected, mortality increased with age, although inversely related to the likelihood of being met by a trauma team. Trauma team activation should be considered for all trauma patients older than 70 years.

Level of evidence Level IV.

\section{BACKGROUND}

Life expectancy in high-income countries is steadily increasing, and consequently, the number of geriatric trauma patients will rise. ${ }^{1-4}$ Elderly patients present a challenge to trauma care not only because of their increasing numbers. The geriatric patient has limited physiologic reserves and often presents with comorbidities and preinjury medication associated with increased risk of complications and death. ${ }^{5-7}$ Already two decades ago, mortality was shown to be doubled in patients older than 65 years compared with younger patients with equivalent injury severity. ${ }^{8}$ Shortly thereafter, old age was suggested to be a criterion for trauma team activation $^{9}$ and such a strategy has recently been shown to be associated with decreased mortality. ${ }^{10}$ However, undertriage of the elderly trauma patients are still reported by several studies in the USA. ${ }^{11-14}$

In line with international trends, our initial treatment of trauma patients has changed substantially during the last 15 years with increased focus on a multidisciplinary approach, updated Damage Control Resuscitation (DCR) protocols, and interventional radiology associated with improved outcomes overall and in subgroups of patients with specific injuries. ${ }^{15-18}$ However, whether there has been an improvement in outcome in the elderly trauma population during the same period has not been explored and constitutes one aim of the present study. Additionally, we wanted to assess whether there has been a change in the proportion of elderly trauma patients met by multidisciplinary trauma teams during the study period.

\section{METHODS}

Oslo University Hospital Ulleval (OUHU) is a major Scandinavian trauma center with a catchment area of approximately 3 million people covering the southeastern part of Norway. The number of admissions has increased gradually with 1755 trauma team activations in 2013 versus 656 in 2002 . Approximately 90\% have sustained blunt trauma and approximately $30 \%$ are severely injured with an Injury Severity Score (ISS) more than 15.

We performed a retrospective study of all trauma patients $>60$ years admitted to OUHU and included in Oslo University Hospital Trauma Registry (OUH-TR) during the 12-year period, 2002-2013. OUH-TR includes all trauma patients admitted through trauma team activation, patients with penetrating injuries proximal to elbow or knee, or patients with ISS $>9$ admitted to OUHU directly or via local hospital within 24 hours after injury.

From the OUH-TR, we extracted age, gender, mechanism of injury (MOI), date of injury, Glasgow Coma Scale (GCS) score, admission systolic blood pressure (SBP), heart rate (HR), base deficit (BD), ISS, anatomic injury classified according to the Abbreviated Injury Scale (AIS) 1998, ${ }^{19}$ preinjury physical status according to the American Society of Anesthesiologists physical status classification system (PPS-ASA), ${ }^{20} 21$ transfusions prior to admission in the intensive care unit (ICU), team activation rate, hospital length of stay (LOS), LOS in ICU, probability of survival (Ps) calculated according to the Trauma and Injury Severity Score methodology 
with coefficients published from the National Trauma Data Bank in 2005, 22 30-day mortality, and main cause of death. Survival status 30 days after injury was obtained from patient records and the Norwegian Population Registry. A patient with an ISS $>15$ not met by a multidisciplinary trauma team at admission was defined as undertriaged. Trauma team activation rate is the percentage of elderly patients included in the OUH-TR and admitted with trauma team activation.

The study population was analyzed for differences between the periods 2002-2009 (period 1 (P1)) and 2010-2013 (period 2 (P2)). The cut-off point was chosen to reflect effects of institutional changes in trauma organization including improved DCR strategies with an updated massive hemorrhage protocol ${ }^{23}$ and the implementation of the regional trauma system with defined triage and transfer criteria. Furthermore, the study cohort was stratified into three groups based on age: 61-70, 71-80, and $>80$ years of age and subjected to subgroup analyses.

Continuous data are presented as medians with IQR. Comparisons between groups were performed using Mann-Whitney U test. Categorical data are reported as proportions and tested for significance using Pearson's $\chi^{2}$ test. For all analyses, a $\mathrm{p}$ value $<0.05$ (derived from a two-tailed test) was considered to indicate significance.

A forward stepwise selection of significant covariates including potential confounders was performed to identify variables independently associated with 30-day mortality. The variables selected for univariate analysis were: period, age, GCS, PPS-ASA (defined as low risk 1-2 and high risk 3-5), ISS, BD, PR, SBP, gender, transfusions, team activation, and MOI (defined as high and low energy). These core variables were then applied to construct a multiple logistic regression model evaluating factors affecting mortality. All variables were prespecified and considered clinically important. The fit of the model was measured with the Hosmer-Lemeshow goodness-of-fit-test statistic. Calculation of the accuracy of the test was measured by the area under the receiver operating characteristic curve for the prediction of 30-day mortality. A similar procedure was followed to construct a multiple logistic regression model to identify variables independently associated with trauma team activation. The variables selected for univariate analysis were: period, age, GCS, ISS, PPS-ASA (defined as 1-2 low risk, 3-5 high risk), gender, SBP, PR, transfusions, and MOI (defined as high and low energy trauma).

All statistical analyses were performed using the IBM SPSS V.25. The institutional data protection officer had no objections to the study.

\section{RESULTS}

The study cohort consisted of 2628 patients; $62 \%$ were men and median age was 72 years. MOI was blunt in $96 \%$ of patients, most commonly secondary to falls (59\%), motor vehicle crashes (16\%), and pedestrian hit by motor vehicle (7\%).

\section{P1 compared with P2}

P1 included 1411 patients and P2 included 1217 patients. Demographic and outcome data are presented in table 1. Median ISS was 17 in both periods. A total of 841 (60\%) patients in P1 and $662(54 \%)$ in P2 were severely injured with ISS $>15$.

Trauma team activation rates increased from $53 \%$ in $\mathrm{P} 1$ to $72 \%$ in $\mathrm{P} 2(\mathrm{p}<0.01)$, whereas crude mortality decreased from $19 \%$ in $\mathrm{P} 1$ to $13 \%$ in $\mathrm{P} 2(\mathrm{p}<0.01)$. Main cause of death was traumatic brain injury in both periods, $67 \%$ in $\mathrm{P} 1$ and $70 \%$ in $\mathrm{P} 2$, respectively. The figure 1 illustrates a gradual increase in

\begin{tabular}{|c|c|c|c|}
\hline & P1 $(n=1411)$ & $P 2(n=1217)$ & $P$ value \\
\hline Age, years & $72(65-81)$ & $72(66-81)$ & 0.29 \\
\hline Male gender, n (\%) & $886(63)$ & 747 (61) & 0.46 \\
\hline $\mathrm{SPB}, \mathrm{mm} \mathrm{Hg}$ & $145(120-165)$ & $145(121-165)$ & 0.91 \\
\hline GCS & $15(12-15)$ & $15(14-15)$ & $<0.01$ \\
\hline $\mathrm{BD}, \mathrm{mmol} / \mathrm{L}$ & $1.45(-0.50-3.80)$ & $1.90(0.40-3.90)$ & $<0.01$ \\
\hline PPS-ASA & $2(1-3)$ & $2(2-3)$ & $<0.01$ \\
\hline ISS & $17(10-26)$ & $17(10-26)$ & 0.04 \\
\hline Penetrating injury, $\mathrm{n}(\%)$ & $49(4)$ & $43(4)$ & 0.93 \\
\hline Patients transfused, n (\%) & $101(7)$ & $62(5)$ & 0.03 \\
\hline Ps & 0.83 & 0.85 & $<0.01$ \\
\hline LOS ICU, days & $2(1-5)$ & $2(1-4)$ & 0.02 \\
\hline TTA, n (\%) & $749(53)$ & $878(72)$ & $<0.01$ \\
\hline $61-70$ years & $382 / 616(62)$ & $425 / 529(80)$ & $<0.01$ \\
\hline $71-80$ years & $222 / 440(51)$ & $257 / 363(71)$ & $<0.01$ \\
\hline$>80$ years & $145 / 355(41)$ & 196/325 (60) & $<0.01$ \\
\hline Mortality, n (\%) & $266(19)$ & $154(13)$ & $<0.01$ \\
\hline $61-70$ years & 79/616 (13) & $36 / 529(7)$ & $<0.01$ \\
\hline $71-80$ years & $82 / 440(19)$ & 45/363 (12) & 0.02 \\
\hline$>80$ years & 105/355 (30) & $73 / 322(23)$ & 0.04 \\
\hline
\end{tabular}

Values are median and IQR when not stated otherwise.

BD, base deficit; GCS, Glasgow Coma Scale; ISS, Injury Severity Score; LOS ICU, length of stay in the intensive care unit; $\mathrm{P} 1$, period $1 ; \mathrm{P} 2$, period 2; PPS-ASA, preinjury physical status according to the American Society of Anesthesiologists classification system; Ps, probability of survival; SBP, systolic blood pressure; TTA, trauma team activation.

trauma team activation rates accompanied by a reduction in mortality rates during the study period.

\section{Comparison between age groups}

Although there were no significant differences in GCS, BD, ISS, or Ps between the three age groups (table 2), we identified an increase in mortality related to age; $10 \%$ in the age group $61-70$ years, $16 \%$ in the age group $71-80$ years and $26 \%$ in the age group above 80 years, respectively, accompanied by a decrease in trauma team activation rates as shown in the figure 2 . In the subgroups of severely injured patients (ISS $>15$ ), team activation rates were $68 \%$ in the age group $61-70$ years, $57 \%$ in the age group 71-80 years, and 51\% in patients older than 80 years (table 2). When comparing P1 with P2, we found a significant decrease in mortality and increase in team activation rate in all three age groups (table 1).

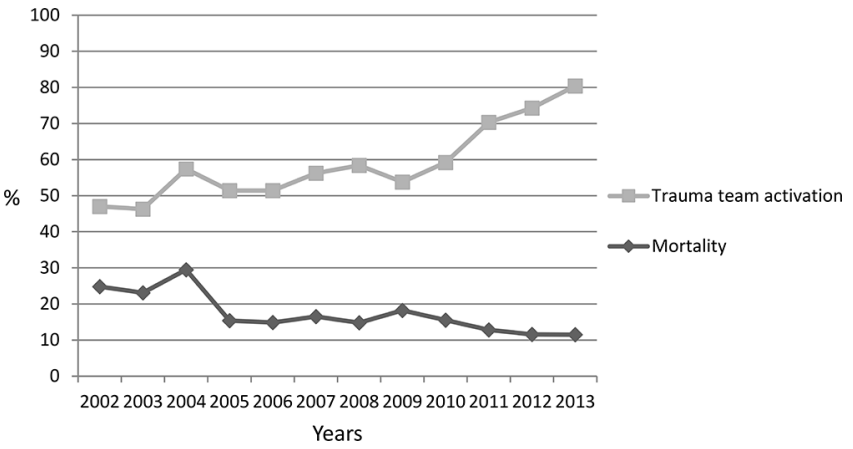

Figure 1 Trends of mortality and trauma team activation rates in the total study population, Oslo University Hospital Ulleval, 2002-2013. 
Table 2 Patient's characteristics stratified by age groups

\begin{tabular}{|c|c|c|c|c|c|}
\hline & $61-70$ years $(n=1145)$ & $71-80$ years $(n=803)$ & P value* & $>80$ years $(n=680)$ & $\mathrm{P}$ valuet \\
\hline Male gender, $\mathrm{n}(\%)$ & $832(73)$ & $484(60)$ & $<0.01$ & $317(47)$ & $<0.01$ \\
\hline $\mathrm{SPB}, \mathrm{mm} \mathrm{Hg}$ & $140(120-160)$ & 145 (123-166) & $<0.01$ & $150(125-170)$ & $<0.01$ \\
\hline GCS & $15(13-15)$ & $15(13-15)$ & 0.42 & $15(13-15)$ & 0.56 \\
\hline $\mathrm{BD}, \mathrm{mmol} / \mathrm{L}$ & $1.75(0.10-3.90)$ & $1.50(-0.40-3.80)$ & 0.10 & $1.70(-0.10-4.00)$ & 0.68 \\
\hline PPS-ASA & $2(1-3)$ & $3(2-3)$ & $<0.01$ & $3(2-3)$ & $<0.01$ \\
\hline ISS & $17(10-26)$ & $17(10-26)$ & 0.11 & $17(10-25)$ & 0.63 \\
\hline Penetrating injury, n (\%) & $57(5)$ & $25(3)$ & 0.04 & $10(2)$ & $<0.01$ \\
\hline Patients transfused, $\mathrm{n}(\%)$ & $76(7)$ & $46(6)$ & 0.42 & $41(6)$ & 0.61 \\
\hline Ps & 0.83 & 0.84 & 0.15 & 0.86 & 0.38 \\
\hline LOS ICU, days & $2(1-5)$ & $2(1-4)$ & 0.06 & $2(0-3)$ & $<0.01$ \\
\hline TTA, n (\%) & $807(71)$ & $479(60)$ & $<0.01$ & $341(50)$ & $<0.01$ \\
\hline In patients with ISS >15 & $438 / 648(68)$ & $278 / 484(57)$ & $<0.01$ & $191 / 373(51)$ & $<0.01$ \\
\hline Mortality, n (\%) & $115(10)$ & $127(16)$ & $<0.01$ & $178(26)$ & $<0.01$ \\
\hline In patients with ISS >15 & 109/648 (17) & $116 / 484(24)$ & $<0.01$ & 140/371 (38) & $<0.01$ \\
\hline
\end{tabular}

Values are median and IQR when not stated otherwise.

* $61-70$ versus $71-80$.

$+61-70$ versus $>80$.

BD, base deficit; GCS, Glasgow Coma Scale; ISS, Injury Severity Score; LOS ICU, length of stay in the intensive care unit; PPA-ASA, preinjury physical status according to the American Society of Anesthesiologists classification system; Ps, probability of survival; SBP, systolic blood pressure; TTA, trauma team activation.

\section{Multiple regression models}

Table 3 presents crude and adjusted ORs, identifying P1, age, GCS, PPS-ASA, ISS, and BD to be independently correlated with 30 -day mortality. The logistic regression model resulted in an OR of 0.77 (95\% CI 0.65 to 0.91 ) for dying when admitted in $\mathrm{P} 2$. The area under the curve (AUC) for the score in the test data set was 0.90 (95\% CI 0.88 to 0.92 ; p < 0.01). The Hosmer-Lemeshow test statistic for model fit was acceptable $\left(\chi^{2}=10.18\right.$, $\mathrm{df}=8, \mathrm{p}=0.25$ ).

Table 4 presents crude and adjusted ORs identifying period, age, GCS, ISS, PPS-ASA, gender, SBP, transfusions, and MOI to be independently correlated with trauma team activation. The logistic regression model resulted in an OR of 2.16 (95\% CI 1.93 to 2.41 ) for being met by a trauma team in P2. The AUC for the score in the test data set was 0.83 (95\% CI 0.81 to 0.85 ; $\mathrm{p}<0.01)$. The Hosmer-Lemeshow test statistic for model fit was acceptable $\left(\chi^{2}=11.38, \mathrm{df}=8, \mathrm{p}=0.18\right)$.

\section{DISCUSSION}

This study demonstrates a decrease in crude mortality in the elderly trauma patients from $19 \%$ in P1 to $13 \%$ in P2. Moreover, a multiple regression model for predicting 30-day mortality identified an OR of 0.77 for dying when admitted in P2. Although many studies have shown increased survival in the adult trauma population related to the development of

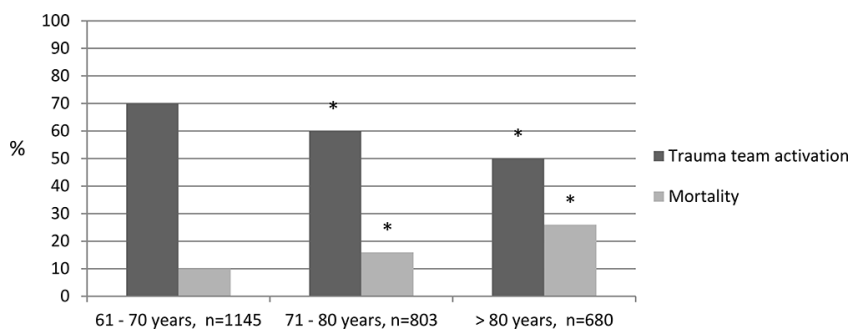

Figure 2 Mortality and trauma team activation rates stratified by age group. Asterisk indicates significant differences $(p<0.05)$ from age group 61-70. trauma systems, ${ }^{24-26}$ to our knowledge, the present study is the first to show a general survival benefit in the geriatric trauma population treated in a single institution. The explanation for the improvements is likely multifactorial since an institutional system is not static over time and mortality decreased gradually throughout the study period (figure 1). During the last 15 years, there has been a continuous dedicated focus on trauma care in our institution. Previously, we have shown that formalization of a dedicated trauma service, development of a clinical governance structure, and performance improvement programme coincided in time with an overall significantly increased survival. ${ }^{17}$ Later, the impact of updated massive transfusion protocols and a more multidisciplinary DCR approach probably contributed to further improvement in outcomes. ${ }^{18}$

Age has been shown to be associated with increased overall mortality after trauma in numerous studies. ${ }^{87-29}$ Due to reduced physiologic reserve, comorbid conditions, polypharmacy including anticoagulant medication, and increased risk of malnutrition the elderly injured patients are at increased risk of complications and death compared with younger patients. ${ }^{5-7} 930-35$ That mortality was more than doubled in patients over the age of 80 compared with the group of patients aged between 61 and 70

Table 3 Logistic regression model for identifying factors influencing mortality

\begin{tabular}{|c|c|c|c|c|c|c|}
\hline & \multicolumn{3}{|c|}{ Crude } & \multicolumn{3}{|c|}{ Adjusted } \\
\hline & OR & $95 \% \mathrm{Cl}$ & $P$ value & OR & $95 \% \mathrm{Cl}$ & $P$ value \\
\hline Period & 0.79 & 0.71 to 0.88 & $<0.01$ & 0.77 & 0.65 to 0.91 & $<0.01$ \\
\hline Age & 1.06 & 1.04 to 1.07 & $<0.01$ & 1.11 & 1.08 to 1.13 & $<0.01$ \\
\hline GCS & 0.74 & 0.72 to 0.76 & $<0.01$ & 0.77 & 0.74 to 0.81 & $<0.01$ \\
\hline PPS-ASA & 1.65 & 1.46 to 1.87 & $<0.01$ & 1.43 & 1.19 to 1.72 & $<0.01$ \\
\hline ISS & 1.08 & 1.07 to 1.09 & $<0.01$ & 1.06 & 1.04 to 1.07 & $<0.01$ \\
\hline$B D$ & 1.16 & 1.12 to 1.19 & $<0.01$ & 1.09 & 1.05 to 1.13 & $<0.01$ \\
\hline
\end{tabular}

BD, base deficit; GCS, Glasgow Coma Scale; ISS, Injury Severity Score; PPS-ASA, preinjury physical status according to the American Society of Anesthesiologists classification system. 
Table 4 Logistic regression model identifying factors influencing trauma team activation

\begin{tabular}{|c|c|c|c|c|c|c|}
\hline & \multicolumn{3}{|c|}{ Crude } & \multicolumn{3}{|c|}{ Adjusted } \\
\hline & OR & $95 \% \mathrm{Cl}$ & $P$ value & OR & $95 \% \mathrm{Cl}$ & $P$ value \\
\hline Period & 1.51 & 1.39 to 1.64 & $<0.01$ & 2.16 & 1.93 to 2.41 & $<0.01$ \\
\hline Age & 0.96 & 0.52 to 0.97 & $<0.01$ & 0.99 & 0.98 to 1.00 & 0.02 \\
\hline GCS & 0.94 & 0.92 to 0.96 & $<0.01$ & 0.90 & 0.87 to 0.93 & $<0.01$ \\
\hline ISS & 1.01 & 1.01 to 1.02 & $<0.01$ & 0.98 & 0.97 to 0.99 & $<0.01$ \\
\hline PPS-ASA & 0.47 & 0.40 to 0.55 & $<0.01$ & 0.56 & 0.45 to 0.70 & $<0.01$ \\
\hline Gender & 0.63 & 0.54 to 0.75 & $<0.01$ & 0.62 & 0.50 to 0.76 & $<0.01$ \\
\hline SPB & 0.99 & 0.99 to 0.99 & $<0.01$ & 0.99 & 0.99 to 1.00 & $<0.01$ \\
\hline Transfusions & 1.61 & 1.35 to 1.92 & $<0.01$ & 1.54 & 1.27 to 1.86 & $<0.01$ \\
\hline MOI & 0.15 & 0.12 to 0.18 & $<0.01$ & 0.13 & 0.10 to 0.16 & $<0.01$ \\
\hline
\end{tabular}

GCS, Glasgow Coma Scale; ISS, Injury Severity Score; MOI, mechanism of injury; PPS-ASA, preinjury physical status according to the American Society of Anesthesiologists classification status; PR, pulse rate; SBP, systolic blood pressure.

years in our study (table 2) was expected. However, mortality was reduced in all three age cohorts from P1 to P2 (table 1), indicating that even the oldest trauma patients benefitted from the institutional improvements in trauma care.

We might speculate that the formalization of a regionalized trauma system with defined triage and transfer criteria in 2010 contributed to the increase in trauma team activation rates (figure 1). Age is not an independent criterion for trauma team activation in these guidelines. The Eastern Association for the Surgery of Trauma's practice management guideline from 2012 recommended lowering the threshold for trauma team activation in patients aged 65 or older. Numerous reports have pointed out that the use of standard triage criteria is followed by undertriage of patients over the age of $60 .{ }^{111} 12142836$ Several studies have tried to demonstrate an effect on undertriage and outcome by redefining trauma criteria for the elderly. ${ }^{13738}$ Brown et al found that substituting SBP of less than $110 \mathrm{~mm} \mathrm{Hg}$ with the current $90 \mathrm{~mm} \mathrm{Hg}$ in patients older than 65 achieves a larger reduction in undertriage than increase in overtriage and the risk for mortality is similar in these groups. ${ }^{39}$ Caterino et al reported the effects of a statewide modification of adult trauma triage criteria to a geriatric substitute by changing cut-off in blood pressure from $90 \mathrm{~mm} \mathrm{Hg}$ to $100 \mathrm{~mm}$ $\mathrm{Hg}$, GCS from 13 to 14 in patients with suspected brain injury, fractures from two or more long bones to one, and introducing additional criteria for injury to two or more body regions, injury from fall from any height with evidence of traumatic brain injury, and pedestrian struck by motor vehicle. ${ }^{40}$ With these changes, they managed to improve sensitivity in identifying older adults in need of trauma center care, but only minor changes in mortality in the group with an ISS less than 10 and no improvement in mortality for the patients with higher ISS. In our study, trauma team activation was not identified as significantly associated with increased survival. Bradburn et al evaluated implementation of two geriatric-specific practice management protocols, the high risk geriatric protocol (HRGP) and the anticoagulation and trauma alert (ACT). ${ }^{33}$ Implementation of the HRGP alone did not have a significant effect on mortality. When combined with ACT, mortality was significantly reduced from $7.24 \%$ to $4.0 \%$. Implementing a separate set of activation criteria for geriatric patients, as described above, would be challenging in most institutions. Hammer et al reported decreased mortality by simply introducing mandatory highest-level trauma activation on arrival in all injured patients 70 years or older regardless of physiology or MOI. ${ }^{10}$ In a recently published follow-up study aiming to identify an age cut-off that conveyed a mortality benefit, the authors reported reduced mortality in patients 77 years or older. ${ }^{3}$ Considering the potential consequences of undertriage in frail elderly, the limited increase in trauma team activations caused by compulsory team activation in all trauma patients 70 years or older seems reasonable.

We found that increased age was inversely related to the likelihood to be met by a trauma team despite the fact that median ISS was 17 in all three age cohorts and thereby that undertriage was most common among the oldest patients (table 2). If our criteria had mandated all patients older than 70 years of age to be met by a multidisciplinary trauma team, the average monthly increase in team activations during the study period would have been 4.6 patients.

There are several limitations to this study including those associated with its retrospective nature. The study design does not allow an evaluation of the influence of undertriage on outcome because differences in case mix and patient volume could influence outcome independent of institutional improvements. The number of patients increased steadily during the study period and may have contributed to a general improvement in trauma care. Higher patient volumes have been associated with increased survival in some studies, whereas others have failed to detect any association between patient volume and mortality. ${ }^{41-44}$

In this retrospective single-center study on geriatric trauma patients, we found decreased mortality and increased proportion of patients examined by a multidisciplinary trauma team compared with historic controls. Increased age was inversely related to the likelihood to be met by a trauma team despite equivalent injury severity. Trauma team activation should be considered for all trauma patients older than 70 years.

Contributors AHR, HR, CG and PAN designed the study. AHR, IAG, NOS, CG and PAN analyzed the data. AHR, CG and PAN conducted the literature search and wrote the article. All authors participated in revising and editing the article.

Competing interests None declared.

Patient consent for publication Not required.

Ethics approval The institutional Data Protection Officer had no objections to the study.

Provenance and peer review Not commissioned; externally peer reviewed.

Open access This is an open access article distributed in accordance with the Creative Commons Attribution Non Commercial (CC BY-NC 4.0) license, which permits others to distribute, remix, adapt, build upon this work non-commercially, and license their derivative works on different terms, provided the original work is properly cited, appropriate credit is given, any changes made indicated, and the use is non-commercial. See: http://creativecommons.org/licenses/by-nc/4.0/.

\section{REFERENCES}

1. Kodadek LM, Selvarajah S, Velopulos CG, Haut ER, Haider AH. Undertriage of older trauma patients: is this a national phenomenon? J Surg Res 2015;199:220-9.

2. Vincent GK VV. The next four decades. the older population in the United States: 2010 to 2050 population estimates and projections. Washington, DC: US Department of Commerce Economics and Statistics Administration, US Census Bureau, 2010:P251138.

3. Carr BW, Hammer PM, Timsina L, Rozycki G, Feliciano DV, Coleman JJ. Increased trauma activation is not equally beneficial for all elderly trauma patients. J Trauma Acute Care Surg 2018;85:1-602

4. Kozar RA, Arbabi S, Stein DM, Shackford SR, Barraco RD, Biffl WL, Brasel KJ, Cooper Z, Fakhry SM, Livingston D, et al. Injury in the aged: geriatric trauma care at the crossroads. J Trauma Acute Care Surg 2015;78:1197-209.

5. Braun BJ, Holstein J, Fritz T, Veith NT, Herath S, Mörsdorf P, Pohlemann T. Polytrauma in the elderly: a review. EFORT Open Rev 2016;1:146-51.

6. Giannoudis PV, Harwood PJ, Court-Brown C, Pape HC. Severe and multiple trauma in older patients; incidence and mortality. Injury 2009;40:362-7.

7. Brown CVR, Rix K, Klein AL, Ford B, Teixeira PGR, Aydelotte J, Coopwood B, Ali S. A comprehensive investigation of comorbidities, mechanisms, injury patterns, and outcomes in geriatric blunt trauma patients. Am Surg 2016;82:1055-62. 
8. Perdue PW, Watts DD, Kaufmann CR, Trask AL. Differences in mortality between elderly and younger adult trauma patients: geriatric status increases risk of delayed death. J Trauma 1998:45:805-10.

9. Demetriades D, Sava J, Alo K, Newton E, Velmahos GC, Murray JA, Belzberg H, Asensio JA, Berne TV. Old age as a criterion for trauma team activation. J Trauma 2001;51:754-7. discussion 6-7.

10. Hammer PM, Storey AC, Bell T, Bayt D, Hockaday MS, Zarzaur BL, Feliciano DV, Rozycki GS. Improving geriatric trauma outcomes: a small step toward a big problem. J Trauma Acute Care Surg 2016;81:162-7.

11. Rogers A, Rogers F, Bradburn E, Krasne M, Lee J, Wu D, Edavettal M, Horst M. Old and undertriaged: a lethal combination. Am Surg 2012;78:711-5.

12. Garwe T, Stewart K, Stoner J, Newgard CD, Scott M, Zhang Y, Cathey T, Sacra J, Albrecht RM. Out-of-hospital and inter-hospital under-triage to designated tertiary trauma centers among injured older adults: a 10-year statewide Geospatial-Adjusted analysis. Prehosp Emerg Care 2017;21:734-43.

13. Newgard CD, Fu R, Zive D, Rea T, Malveau S, Daya M, Jui J, Griffiths DE, Wittwer L, Sahni R, et al. Prospective validation of the National field triage guidelines for identifying seriously injured persons. J Am Coll Surg 2016;222:146-58.

14. Nakamura Y, Daya M, Bulger EM, Schreiber M, Mackersie R, Hsia RY, Mann NC, Holmes JF, Staudenmayer K, Sturges Z, et al. Evaluating age in the field triage of injured persons. Ann Emerg Med 2012;60:335-45.

15. Gaarder C, Dormagen JB, Eken T, Skaga NO, Klow NE, Pillgram-Larsen J, Buanes T, Naess PA. Nonoperative management of splenic injuries: improved results with angioembolization. J Trauma 2006;61:192-8.

16. Gaarder C, Naess PA, Eken T, Skaga NO, Pillgram-Larsen J, Klow NE, Buanes T. Liver injuries - improved results with a formal protocol including angiography. Injury 2007:38:1075-83

17. Groven S, Eken T, Skaga NO, Roise O, Naess PA, Gaarder C. Long-lasting performance improvement after formalization of a dedicated trauma service. J Trauma 2011;70:569-74.

18. Gaski IA, Barckman J, Naess PA, Skaga NO, Madsen JE, Kløw NE, Flugsrud G, Gaarder C. Reduced need for extraperitoneal pelvic packing for severe pelvic fractures is associated with improved resuscitation strategies. J Trauma Acute Care Surg 2016;81:644-51.

19. Gennarelli TA, Wodzin E. AIS 2005: a contemporary injury scale. Injury 2006;37:1083-91.

20. ASA Physical Status Classification System. American Society of Anesthesiologists. 2014; October 15. https://www.asahq.org/standards-and-guidelines/asa-physicalstatus-classification-system.

21. Skaga NO, Eken T, Søvik S, Jones JM, Steen PA. Pre-injury ASA physical status classification is an independent predictor of mortality after trauma. J Trauma 2007;63:972-8.

22. Schluter PJ, Nathens A, Neal ML, Goble S, Cameron CM, Davey TM, McClure RJ. Trauma and injury severity score (TRISS) coefficients 2009 revision. J Trauma 2010;68:761-70.

23. Gaski IA, Skattum J, Brooks A, Koyama T, Eken T, Naess PA, Gaarder C. Decreased mortality, laparotomy, and embolization rates for liver injuries during a 13-year period in a major Scandinavian trauma center. Trauma Surg Acute Care Open 2018;3:e000205.

24. Ashley DW, Pracht EE, Medeiros RS, Atkins EV, NeSmith EG, Johns TJ, Nicholas JM. An analysis of the effectiveness of a state trauma system: treatment at designated trauma centers is associated with an increased probability of survival. I Trauma Acute Care Surg 2015;78:706-12. discussion 12-4.

25. Celso B, Tepas J, Langland-Orban B, Pracht E, Papa L, Lottenberg L, Flint L. A systematic review and meta-analysis comparing outcome of severely injured patients treated in trauma centers following the establishment of trauma systems. J Trauma 2006:60:371-8. discussion 8.

26. Nathens AB, Jurkovich GJ, Rivara FP, Maier RV. Effectiveness of state trauma systems in reducing injury-related mortality: a national evaluation. J Trauma 2000;48:25-30. discussion -1.
27. Morris JA, MacKenzie EJ, Damiano AM, Bass SM. Mortality in trauma patients: the interaction between host factors and severity. J Trauma 1990;30:1476-82.

28. Benjamin ER, Khor D, Cho J, Biswas S, Inaba K, Demetriades D. The age of Undertriage: current trauma triage criteria underestimate the role of age and comorbidities in early mortality. J Emerg Med 2018;55:278-87.

29. de Vries R, Reininga IHF, Pieske O, Lefering R, El Moumni M, Wendt K. Injury mechanisms, patterns and outcomes of older polytrauma patients-An analysis of the Dutch trauma registry. PLoS One 2018;13:e0190587.

30. Cook AC, Joseph B, Inaba K, Nakonezny PA, Bruns BR, Kerby JD, Brasel KJ, Wolf $\mathrm{SE}$, Cuschieri J, Paulk ME, et al. Multicenter external validation of the geriatric trauma outcome score: a study by the prognostic assessment of life and limitations after trauma in the elderly (PALLIATE) Consortium. J Trauma Acute Care Surg 2016;80:204-9.

31. Demetriades D, Karaiskakis M, Velmahos G, Alo K, Newton E, Murray J, Asensio J, Belzberg H, Berne T, Shoemaker W, et al. Effect on outcome of early intensive management of geriatric trauma patients. Br J Surg 2002;89:1319-22.

32. Hashmi A, Ibrahim-Zada I, Rhee P, Aziz H, Fain MJ, Friese RS, Joseph B. Predictors of mortality in geriatric trauma patients: a systematic review and meta-analysis. J Trauma Acute Care Surg 2014;76:894-901.

33. Bradburn EH, Gross BW, Jammula S, Adams WH, Miller JA. Improved outcomes in elderly trauma patients with the implementation of two innovative geriatric-specific protocols-Final report. J Trauma Acute Care Surg 2014;76:894-901. 2018;84(2):3017.

34. Campbell-Furtick M, Moore BJ, Overton TL, Laureano Phillips J, Simon KJ, Gandhi RR, Duane TM, Shafi S. Post-trauma mortality increase at age 60: a cutoff for defining elderly? Am J Surg 2016;212:781-5.

35. Goodmanson NW, Rosengart MR, Barnato AE, Sperry JL, Peitzman AB, Marshall GT. Defining geriatric trauma: when does age make a difference? Surgery 2012;152:668-75. discussion 74-5.

36. Chang DC, Bass RR, Cornwell EE, Mackenzie EJ. Undertriage of elderly trauma patients to state-designated trauma centers. Arch Surg 2008;143:776-81.

37. Ichwan B, Darbha S, Shah MN, Thompson L, Evans DC, Boulger CT, Caterino JM. Geriatric-specific triage criteria are more sensitive than standard adult criteria in identifying need for trauma center care in injured older adults. Ann Emerg Med 2015;65:92-100.

38. Nishijima DK, Gaona SD, Waechter T, Maloney R, Bair T, Blitz A, Elms AR, Farrales RD, Howard C, Montoya J, et al. Out-of-Hospital Triage of Older Adults With Head Injury: A Retrospective Study of the Effect of Adding "Anticoagulation or Antiplatelet Medication Use" as a Criterion. Ann Emerg Med 2017;70:127-38.

39. Brown JB, Gestring ML, Forsythe RM, Stassen NA, Billiar TR, Peitzman AB, et al. Systolic blood pressure criteria in the National Trauma triage protocol for geriatric trauma: 110 is the new 90. J Trauma Acute Care Surg 2014;76:894-901. 2015;78(2):352-9.

40. Caterino JM, Brown NV, Hamilton MW, Ichwan B, Khaliqdina S, Evans DC, Darbha S, Panchal AR, Shah MN. Effect of Geriatric-Specific trauma triage criteria on outcomes in injured older adults: a statewide retrospective cohort study. J Am Geriatr Soc 2016;64:1944-51.

41. Bell TM, Boustany KC, Jenkins PC, Zarzaur BL. The relationship between trauma center volume and in-hospital outcomes. J Surg Res 2015;196:350-7.

42. Glance LG, Osler TM, Dick A, Mukamel D. The relation between trauma center outcome and volume in the National Trauma Databank. J Trauma 2004:56:682-90.

43. Minei JP, Fabian TC, Guffey DM, Newgard CD, Bulger EM, Brasel KJ, Sperry JL, MacDonald RD. Increased trauma center volume is associated with improved survival after severe injury: results of a resuscitation outcomes Consortium study. Ann Surg 2014;260:456-64. discussion 64-5.

44. Nathens AB, Jurkovich GJ, Maier RV, Grossman DC, Mackenzie EJ, Moore M, Rivara FP. Relationship between trauma center volume and outcomes. JAMA 2001;285:1164-71. 